\title{
SOBRE LOS MECANISMOS DE IMPERSONALIZACIÓN EN LA CONVERSACIÓN COLOQUIAL: EL TÚ IMPERSONAL."
}

\author{
Antonio Hidalgo Navarro \\ (Universidad de Valencia)
}

\begin{abstract}
RESUMEN
This article treats about one of the numerous peculiarities of the spoken language. We are going to analize the use of the pronominal second person as a pragmalinguistic mechanism of generalization in the present Spanish norm. Those grammatical uses need a specific explanation beyond the limits of the traditional grammar, because from this view they cannot be justified. We have to search this explanation in the scope of the Pragmatics.
\end{abstract}

El trabajo que nos proponemos presentar tiene como punto de referencia un marco estilístico concreto, el llamado «lenguaje coloquial», entendido como Nivel de Habla, es decir, como forma de expresión lingüística oral determinada por la necesidad comunicativa humana, que tiene su manifestación más genuina y directa en la conversación o diálogo'.

Nuestro corpus ${ }^{2}$ de partida ha sido, por tanto, íntegramente oral, basado en la lengua hablada, y más concretamente en grabaciones magnetofónicas donde se

* Este trabajo parte de una comunicación anterior, «El registro coloquial en la didáctica de la lengua. Un caso particular: Tú impersonal», que presenté en el $I$ Congreso Internacional de Enseñanza del Español, celebrado en Madrid del 27 al 31 de enero de 1992.

Para la mayoría de estudiosos es admisible igualmente la recogida de datos coloquiales o identificables con la lengua coloquial en textos escritos; de hecho hay una extensa bibliografía referida al estudio de la lengua coloquial española tomando como base tales fuentes. Basta confrontar trabajos como los de W. Beinhauer (1964), F. Díaz (1985), C. Hernández (1980), L. A. Hernando Cuadrado (1988), M. C. Lasaletta (1974), T. Sandru (I988), M. Seco (1989), B. Steel (1985) y otros muchos. Nuestra opinión, sin embargo, es la de que no hay que olvidar que el coloquio literario no hace más que reproducir aproximadamente la estructura general del coloquio real, que aparece en las conversaciones reales y espontáneas. Por esta razón consideramos plenamente acertadas las palabras de M. Criado ( $1980: 15)$ cuando afirma que «es el coloquio real el que ante todo nos interesa, no porque deje de ser valioso el literario, sino porque éste depende de aquél (...)»

2 Nuestro corpus de partida forma parte del corpus de español hablado en fase de elaboración por el grupo de investigación Val. Es. Co. (Valencia, Español Coloquial), del Dpto de Filología Española de la Universidad de Valencia. 
daban las condiciones propias del registro coloquial.

No vamos ahora a hacer una descripción exhaustiva en torno al escurridizo concepto de registro coloquial (no es éste el objetivo que nos hemos planteado al comenzar nuestro análisis), aunque sí creemos oportuno anotar algunos de los rasgos más generales señalados por la bibliografía al uso; sólo así podrán llegar a entenderse algunos de los fenómenos referidos a la persona de la enunciación, verdadero objeto de nuestro presente estudio.

Así, uno de los rasgos característicos del denominado español coloquial es, de acuerdo con E. Lorenzo (1977:173) el egocentrismo del emisor, que dicho autor sitúa entre las variables de dicho registro de habla, al que se añaden otras dos características también variables:

a) el carácter deíctico del español coloquial (posiblemente más intenso en español que en otras lenguas);

b) la experiencia común, cambiante según el grado de complicidad de los hablantes ${ }^{3}$, que determina:

A estas tres variables se añaden dos características constantes:

a) la presencia física de una o más personas con cuya atención, iniciativa o reacción (oral o no) cuenta el hablante;

b) un marco espacial y temporal que sirve de referencia a toda la comunicación.

Posiblemente, de todos los elementos anteriores merece una consideración esencial la «participación y función común y directa de dos o más interlocutores» ${ }^{4}$. Tal como propone M. Criado de Val (1980:19) el plano dominante en este registro es el de la subjetividad (YO)/tiempo presente (AHORA)/espacio inmediato (AQUí).

En último término las diversas propuestas no difieren esencialmente del esquema comunicativo básico que podemos esbozar como sigue:

\section{EMISOR (YO) -relación comunicativa- RECEPTOR (TÚ)}

donde alternativamente el emisor se transforma en receptor y el receptor (receptores) en emisor (emisores) según los avances del diálogos.

3 Esta experiencia común condiciona ciertas selecciones léxicas y/o gramaticales por parte del hablante. Así, E. Lorenzo (p. 173) menciona:

- la presencia de ciertos pronombres/proverbos con función anafórica,

- la perspectiva de presente (actualización, recursos en que el enlace gramatical y conceptual con lo pasado está diluido: hicieron de las suyas; o desemboca en el vacío: las pasó canutas).

$4 \quad$ Cfr. al respecto M. Criado de Val (1980:14).

$5 \quad$ Al respecto hay que anotar la opinión de J. Lyons (1980:575) para quien «la función del hablante se transfiere de un participante al otro a medida que progresa la conversación y los participantes pueden moverse en el curso de la misma (...)». 
Sentadas las bases coloquiales de nuestro corpus, sustentado sobre 11 horas de grabación secreta y no secreta ${ }^{6}$, en las líneas siguientes intentaremos deslindar un comportamicnto específico en el sistema de pronombres personales en español que parece apartarse del supuesto egocentrismo del español coloquial. Nos referimos al uso por parte del sujeto de la enunciación (siempre YO) del pronombre de $2^{a}$ persona (TÚ) o la segunda persona del singular del verbo ${ }^{7}$, con referencia indeterminada hacia un sujeto que no corresponde al receptor realmente presente en cl diálogo, sino que su referencia se extiende a «toda la raza humana», en palabras de M. Seco (1989: 374) ${ }^{8}$.

¿A qué obedecen tales usos? ¿Cómo justificarlos? ¿En qué gramática hallar su fundamento lingüístico?

Creemos significativo al respecto el hecho de que la inmensa mayoría de gramáticas consultadas no recoja en su inventario de funciones de las formas pronominales-sujeto este empleo desplazado de la $2^{\text {a }}$ persona del singular. No lo hemos hallado en A. Bello $(1850,1853,1857,1860=1981)$, ni en R. J. Cuervo (1867=1954), pese a que este último sí señala usos del lenguaje hablado bogotano; tampoco la RAE, ni en su Gramática de 1931 ni en el Esbozo (1973=1980) recoge este uso, aun cuando en este último aparece novedosamente la definición de sincretismo, entendido como proceso por el cual dos o más miembros de un mismo paradigma resultan funcionalmente diferentes y formalmente iguales. Se aplica este concepto en el Esbozo a los sincretismos de los pronombres personales átonos (leísmo), y nosotros nos preguntamos si acaso no

- Sobre la aceptabilidad de grabaciones secretas como método para recopilar datos orales coloquiales algunos autores como A. M² Vigara Tauste (1980:30) hacen ver ciertos inconvenientes:

«(..) si para evitar que los hablantes se sientan condicionados se quiere mantener oculta la grabación será difícil que ésta sea buena, y en último término, aunque ésta sea perfectamente inteligible y clara, faltarán en la muestra muchos de los condicionamientos y estados propios del coloquio, que sólo en su estricta actualización y momentaneidad aparecen y se entienden (...)».

Frente a esta opinión se sitúan otras más positivas como la de A. Narbona (1988:92) quien, no sólo admite tales grabaciones secretas como perfectamente válidas (siempre que unas condiciones exteriores ajenas a ruidos o interferencias y un aparato idóneo permitan una adecuada captación de los materiales orales hablados), sino que además no rechaza de plano las grabaciones en que los informantes conocen que están siendo grabados, puesto que «el recelo y la preocupación por esforzarse en hablar....apenas se produce en las capas inferiores, a lo sumo, puede ser aconsejable prescindir de los minutos iniciales, de tanteo, de la conversación, que en seguida comienza a discurrir con naturalidad y fluidez. Ni siquiera hay por qué recurrir al procedimiento de grabar con total desconocimiento por parte de los interlocutores (...)» Para una mejor y más detallada visión tipológica sobre las posibilidades metodológicas tanto en lo que atañe a conversaciones grabadas secretamente como no secretamente, remitimos al lector a los interesantes comentarios respectivos de M. Criado de Val (1980:67-71) y C. Silva-Corvalán (1988:14-46).

7 Es decir, la referencia de persona se halla tanto en los pronombres como en los morfemas de $n^{\circ}$-persona del verbo.

\& Algunos trabajos que han analizado el problema desde posturas diversas corresponden a J. R. Stamm (1967), M. Gorosch (1967) o E Lorenzo (1984). 
tiene el mismo carácter sincrético el caso de TÚ, referido al interlocutor-oyente, por un lado, e indicador de sujeto indeterminado, por el otro.

Ni R. Lenz (1935) ni R. Seco (1954=1982) señalan este uso desplazado. Para el segundo (pp. 43-46) tanto YO como TÚ hacen referencia a personas presentes en la conversación, afirmación paradójica si tenemos en cuenta que TÚ en la conversación coloquial puede hacer referencia a alguien no presente físicamente en el diálogo.

S. Gili Gaya (1976, $11^{\mathrm{a}}$ ed.) propone el concepto de discordancia deliberada para referirse al hecho de que

«a veces nos dirigimos a un sujeto singular con el verbo en plural para obtener un efecto estilístico deliberado, bien sea para participar amablemente en la actividad o estado de nuestro interlocutor, bien con intención irónica».

Una pregunta como ¿cómo estamos?, dirigida a un individuo enfermo resulta bastante ilustrativa como ejemplo de estos procesos. Otros usos recogidos por el autor son los plurales de modestia, el plural mayestático y ciertos demostrativos neutros indicativos de menosprecio (eso referido a personas).

Aunque parezca extraño Gili Gaya no recoge el empleo de TÚ con sujeto indeterminado cuando también éste podríamos considerarlo como caso de discordancia deliberada.

Finalmente, en esta rápida revisión de la gramáticas al uso hemos de decir que tampoco F. Marcos Marín (1978) y (1980=1984) ni Alcina-Blecua refieren este uso entre los hábitos del castellano hablado.

La excepción a este marco general de interpretaciones la representa con agudeza la figura de M. Seco (1989: 163, n. 11) quien tiene muy en cuenta que uno de los usos más frecuentes de la segunda persona en español coloquial es el impersonal (valor que comparte con el indefinido UNO):

«(...) en el uso coloquial de hoy, el valor impersonal de uno es asumido frecuentemente por el pronombre personal tú y la forma «tú» del verbo: Vas por la calle tan tranquilo y te cortan el paso ».

¿A qué se debe este «extraño» acierto? Pues sencillamente a algo que el mismo M. Seco advierte, esto es, al hecho de que toma como fuente de su reflexión en este caso, el papel de la segunda persona en la «lengua hablada».

Creemos que este vacío de las gramáticas al uso (salvaguardando la opinión recogida por $M$. Seco) debe subsanarse cuando se trata de dar un enfoque didáctico del uso hablado, máxime si nos situamos ante la enseñanza del español como lengua extranjera ${ }^{9}$. Constituye un uso que necesariamente debe

Entre los manuales que hemos manejado quisiéramos citar la gramática de $\mathrm{P}$. Vanden Bulcke (1991:82), J. Butt y C. Benjamin (1988:308) y R. Sarmiento y A. Sánchez (1989:90), quienes se hacen efectivamente eco del uso que ahora analizamos. 
ser estudiados y justificado, puesto que no se trata en ningún caso de variantes sociolingüísticas, sino estilísticas o de registro, a saber, características del registro coloquial (o español hablado en el amplio sentido del término). En definitiva, un conocimiento completo del español como lengua extranjera (y también, evidentemente, como lengua materna), exige la inclusión en los métodos de enseñanza de usos lingüísticos determinados estilísticamente. Sólo si se dominan los diversos registros o «diferencias entre los tipos de modalidad expresiva, según las circunstancias constantes del hablar (hablante, oyente, situación u ocasión del hablar y asunto del que se habla)» ${ }^{10}$, podrá afirmarse que un individuo dispone de un conocimiento de la expresión lingüística (del uso) oral aceptable.

El hecho de que determinados usos característicos de la lengua hablada (del español hablado), entendida ésta como equivalente de lengua o registro coloquial tal como considera F. Lázaro Carreter $(1974)^{11}$, no aparezcan recogidos en nuestras gramáticas (el uso de TÚ con indeterminación de sujeto es un ejemplo de tales construcciones), tiene su justificación en el tradicional fundamento de aquéllas en la lengua escrita y más exactamente en la lengua literaria. A ello aluden los comentarios de autores como A. Ma Vigara (1980:19), para quien los fenómenos coloquiales difícilmente pueden interpretarse

$\ll(\ldots)$ por los moldes de la gramática tradicional, sólo teórica, de escasa base real $(\ldots) »$,

y carente de una terminología precisa y eficaz para aplicar a los fenómenos específicamente coloquiales; o A. Narbona (1986:325), para quien las gramáticas tradicionales se caracterizan

«(...) por la escasa utilidad de los instrumentos conceptuales- teóricos o metodológicos- (...) a la hora de reconocer y estudiar la estructuración sintáctica de un texto hablado espontáneo (...)».

En este sentido uno de los principales motivos de desfase entre las gramáticas al uso y una futurible gramática del coloquio radica en que aquéllas

«se hayan centrado en el enunciado y hayan prestado escasísima atención a la enunciación (Narbona, 1986:267)».

10 Cfr. E. Coseriu (1981:12).

11 Este autor establece una definición equivalente para los términos de lengua coloquial y uso lingüístico. Así, define este último como «empleo medio que los hablantes hacen de la lengua», siendo la lengua de uso (al. Untgansprache, ing. slang, fr. langue d'usage) la «modalidad lingüística que utilizan los hablantes de una lengua en sus relaciones cotidianas. Se opone a lengua especial. Se denomina también lengua coloquial, y no debe confundirse con lengua vulgar (= lengua del vulgo inculto)». 
Así pues, sólo a partir de textos orales, de transcripciones coloquiales, es posible acceder a los fenómenos lingüísticos peculiares de la enunciación.

Ello no ha impedido que ciertos autores se hay an apercibido de este fenómeno sobre la base de textos coloquiales escritos, como son los casos de W. Beinhauer (1985:166, nota 45), que alude a un proceso por el cual el hablante atribuye la actividad expresada por el verbo al interlocutor (No te das cuenta. $Y$ de pronto te encuentras con que te han engañado. Luego te convences de que es inútil ) o Ch. E. Kany (1969:129) para quien

«otra peculiaridad de USTED (junto con el TÚ) tanto en español americano como en el peninsular, es su frecuente uso en expresiones impersonales, análogo al uso del inglés YOU en el sentido de uno".

Veamos algunos ejemplos obtenidos de nuestro corpus; obsérvese la alternancia constante de la primera y segunda personas a lo largo de los mismos:

A)

«...y aparte que yo te lo digo, vas a cualquier sitio, nano, y te jodes...vas a otro sitio...y... y...pides...pides...pides ginebra, con coca cola y te dan...larios, y te dan coca-cola. Luego ahí te da el tío ginebra Milton y pepsicola, tío...pides...pides vodka y te dan smirnoff, tío, y y fanta naranja, no te dan mirinda, tío y vodka...Pepe, nano, porque la vodka de ahí no tiene ni nombre, nano. Pides, tío, snap y no, y ahí tienen...»

B)

«...es que mira, no hay cosa que...que más me rebote que tener la sensación de que estoy perdiendo el tiempo...Y. Yo, si hago algo a conciencia yo me podré equivocar o no, pero lo hago porque he querido... pero eso de que me obliguen a hacer una cosa y que además que veas que no sirve para nada, es muy fuerte... y bueno, y aguantas tres meses, cuatro, cinco...pero los los últimos meses son críticos ¿eh? son críticos, a no ser que seas un borrego que lo hagas todo y sí buana...en ese caso pues no vas a tener ningún problema...»

C)

«...o sea... es que disfrutas de ver que has ayudado a alguien... que yo he hecho algo que, o sea, que no lo hago por mí, ni mi satisfacción personal, ¿no?, pero que dices, oye hay una persona pues que le he ayudado a esto, que le he enseñado lo otro...y de hecho, yo qué sé, yo decía y...cada vez que, a medida que te vas metiendo es como un vicio un poco, a medida que te vas metiendo te va gustando más, y tú luego qué pasa, que hay veces que dices, no pues hoy no, no me apetece hacer nada y tal y cual...y entonces, cuando te empiezas a dejar, entonces...vas viendo que todo te cuesta más y entonces dices...realmente, o sea, es que me estoy dando cuenta que estoy haciéndolo mal, soy egoísta...» 
La lectura de M. Seco (1985, $4^{\text {a }}$ ed.) induce a reflexionar acerca de la naturaleza de estas interferencias entre forma y función pronominales para la segunda persona. Analiza este autor ciertos rasgos coloquiales en la novela Entre visillos de C. Martín-Gaite, entre los que incluye un apartado dedicado a este asunto considerándolo como caso de Indefinición de Sujeto, usual

«en la conversación como recurso con que la modestia o la timidez eluden la mención del YO bajo un disfraz de «cualquiera», de manera que el caso individual tiende a diluirse en una categoría universal» (p. 374).

En este caso

«el deseo de encadenar al oyente al interés del YO hace que éste transfiera lingüísticamente a aquél sus propias vivencias, de modo que la actitud abstratizante que hace solidaria del hablante a toda la raza humana se vierte en el molde concreto del único representante actual de ésta, que es el TU del que escucha $(. .)$.$» .$

El mismo M. Seco (1985:379) cita a J. Costa y A. Redondo (1965) como autores que también recogen tal empleo, si bien para ellos el uso de la segunda persona del singular con valor impersonal en la lengua familiar

«n'est toutefois possible que si la phrase est déjà IMPERSONELLE, car, dans le cas contraire, la deuxième personne garderait sa valeur d'origine».

Por supuesto este empleo de la segunda persona del singular para indicar impersonalidad no es exclusiva del castellano. Así, E. Lorenzo (1989:229) constata como rasgo característico del inglés la desaparición hace siglos de las formas históricas de $2^{a}$ persona del singular (Thou, Thee, thy- tú, te, tú) empleándose $Y O U$ ( $2^{a}$ persona objeto del plural) como forma única de $2^{a}$ persona y también como forma impersonal.

$M^{2}$. A Alvarez (1989:39) menciona el empleo de la forma (TÚ) y las átonas correspondientes como impersonales como fenómeno análogo al francés on, o al alemán man, en la idea de que TÚ impersonal resulta equivalente a uno impersonal:

«...un asco, vamos, pero a mí eso me parece un asco, vamos, o sea...un asco, hombre, conforme a mis expectativas de diversión, porque yo tengo veintitrés años y yo veo que no pego ahí... y cómo conoces (conoce uno) a una tía hoy en día, nano, dónde te tienes (se tiene uno) que meter para buscar una... una chica legal, tío, o sea, legal como tú (uno), coño... ${ }^{12}$

: Ejemplos extraídos de nuestro corpus. 
A este mismo empleo corresponden las formas inglesas one y a fellow reseñadas por O. Jespersen (1975: 258). El autor (p. 257) justifica esta expresión aduciendo que el hablante (YO) en ocasiones prefiere dejar su persona

«en el fondo a pesar de que lo que se expresa es la primera persona más que otra cosa».

Volviendo a la lengua española, según E. Lorenzo (1989:219) el llamado Tú impersonal y su frecuencia en el coloquio se hallan en relación con el desplazamiento experimentado por la división tradicional TÚ/USTED en el sistema de tratamientos pronominales del español. Así, se observa una tendencia al tuteo generalizado especialmente considerable en el registro coloquial ${ }^{13}$. Pues bien, para el autor tal comportamiento (el tuteo) ha conducido a la hiperutilización del pronombre TÚ (de la $2^{\mathbf{a}}$ persona en general) en casos no habituales como, precisamente, el del TÚ impersonal, para el que E. Lorenzo (p. 220) postula un origen levantino ${ }^{14}$.

Desde luego el uso no es nuevo, y podríamos retrotraernos al latín vulgar o al protorromance (v. g. Itinerarium Egeriae : «Putares canem leporem persequi» apud Grandgent (1928); también V. Väänänen (1968=1985) alude al empleo de la $2^{a}$ persona del singular de la voz activa para expresar impersonalidad como característica de la morfosintaxis verbal latino-vulgar (p. 225):

Videas (= podéis ver),

diceres (= se dice).

Son por tanto tendencias cuyos orígenes podemos remontar en muchos siglos a la época actual. La novedad radica, sin duda, en la frecuencia con que tal uso sobreviene en el habla cotidiana sin que podamos interpretarlo como vulgarismo o barbarismo.

Pero más allá de sus orígenes históricos o geográficos lo que realmente interesa es justificar lingüísticamente un empleo tan característico del español hablado, siendo como es una «desviación» de lo que tradicionalmente nos ofrecen las gramáticas al uso.

Conducentes a intentar justificar estos usos son las propuestas de J. Vicente Mateu (1990) y E. V. Enríquez (1984). Extraña no obstante que un estudio tan pormenorizado como el de P. Rosengren (1974) no recoja ningún ejemplo de este TÚ impersonal, aunque posiblemente la causa radica en su corpus extraído exclusivamente de fuentes literarias (12 obras de teatro escritas y estrenadas

13 Cfr. al respecto V. Alba de Diego y J. Sánchez Lobato (1980)

14 Sin embargo, para M. Seco (1985:379, nota 16) el uso no es tan reciente como aprecia E. Lorenzo (años cuarenta); aduce un ejemplo de Cervantes: «...De los alguaciles dijo que no era mucho que tuviesen algunos enemigos, siendo su oficio, o prenderte, o sacarte la hacienda de casa, o tenerte en la suya en guarda y comer a tu costa...» El licenciado Vidriera, Clásicos Castellanos 36 , Madrid 1957,73 ), con lo que resulta más difícil de admitir el supuesto origen levantino de la estructura. 
entre 1945-1968). Resulta al respecto paradójico que se identifique el registro de tales documentos teatrales con un «lenguaje coloquial» y sin embargo no aparezca un uso tan extendido y característico del coloquio como el de TÚ con indeterminación de sujeto (TÚ = cualquiera, NO-YO).

Pero revisemos las propuestas de ambos autores.

1. E. V. Enríquez (1980:55-60) basa su estudio íntegramente en datos orales a partir de los cuales observa abundantes interferencias personales entre los pronombres-sujeto, consistentes en la referencia a una persona conceptual haciendo uso de un elemento personal que no le corresponde directamente (en esencia csto es lo que ocurre con el Tú impersonal).

Algunos usos en que se da la indeterminación del sujeto de la enunciación (como los del plural nosotros mayestático o los plurales de modestia) son exclusivos de la lengua escrita, lo que justifica la presencia de estos usos en la inmensa mayoría de gramáticas a nuestro alcance, apoyando esto en consecuencia nuestra idea de partida: el hecho de que aquéllas se han venido centrando casi exclusivamente en la lengua escrita para la mayor parte de comportamientos lingüísticos.

Para C. Bobes (apud E. Enríquez) la referencia del YO mediante formas ajenas supone la apertura del vínculo del $\mathrm{YO}$ al conjunto de personas que forman el $\mathrm{NO}-\mathrm{YO}$, ya sea una apertura parcial ( $\mathrm{YO} / 1^{\mathrm{a}}$ persona plural), apertura hacia el oyente (se adopta el punto de vista del oyente), o un alejamiento total del discurso (objetivización del YO motivado por un deseo de generalización).

Todo ello hace concluir a Enríquez, y compartimos su postura, que el mecanismo de interferencias de persona puede reducirse a un juego inclusivoexclusivo de las personas enunciativas respecto de la situación comunicativa, es decir, a un mayor o menor distanciamiento entre los interlocutores. En este caso si lo que se pretende es difuminar la idea de los participantes en la comunicación se obtienen los valores indeterminados (de los que el TÚ impersonal es un caso particular). Al respecto la autora propone una progresiva gradación en la que se va ganando en indeterminación:

- la $1^{\mathrm{a}}$ persona puede sustituirse por la $2^{\mathrm{a}}$ o la $3^{\mathrm{a}}$ : YO $/ \mathrm{TÚ} / 3^{\mathrm{o}}$ persona $=$ $\mathrm{UNO}$;

- la $2^{\circ}$ persona por la $3^{\mathrm{a}}$ : TÚ $/ 3^{\circ}$ persona $=\mathrm{UNO}$;

- la $3^{a}$ persona expresa generalización o indeterminación absoluta y desaparece, pues, de la esfera comunicativa ${ }^{15}$.

15 Consideramos que la explicación completa de la gradación propuesta por Enríquez exigiría un estudio pragmático pormenorizado y empírico (sobre la base de conversaciones coloquiales reales). En nuestra revisión del fenómeno sólo hemos pretendido plantear una frecuencia de uso del español hablado, sin llegar a su caracterización completa. en todo caso, pensamos profundizar en este análisis en posteriores trabajos sobre el asunto. Es, por otro lado, de todos conocido, que en la conversación coloquial los mecanismos de impersonalización son abundantes, sobre todo si tenemos en cuenta como factor impulsor de los mismos la cortesía verbal. 
El hablante, en consecuencia, utiliza todas las formas que el NO-YO le ofrece en castellano para conseguir difuminar su personalidad de hablante; dado que los usos de TÚ no implican una indeterminación total ni una referencia directa al hablante, quizás sería más adecuado hablar de generalización que de indeterminación de sujeto.

En definitiva, lo que a nuestro parecer resulta más destacable en todo cl estudio de la autora, es la enorme frecuencia con que aparece la $2^{a}$ persona con referencia generalizadora (en el caso del pronombre TÚ un $26{ }^{\prime} 22 \%$ con referencia generalizadora, pero en el caso de las segundas personas verbales un $66^{\prime} 11 \%$ con referencia generalizadora frente a un $33^{\prime} 88 \%$ con referencia al oyente-interlocutor, [pp. 175-176 y p. 176, nota 2]), proporciones lo suficientemente significativas, pensamos, como para que su uso comience a ser tratado en las descripciones gramaticales del español ${ }^{16}$.

2. J. A.Vicente Mateu introduce una propuesta de análisis pragmático con el fin de abordar este tipo de fenómenos que afectan a la deíxis personal. Tiene en cuenta (p. 196) siguiendo a G. Rauh (1984), el carácter egocéntrico de la determinación deíctica (de la que la deíxis personal se constituye como una manifestación más) junto al carácter dialógico del acto de habla, aspectos que determinan ciertos resultados que debemos abordar en el terreno de la pragmática.

Pues bien, teniendo en cuenta tales premisas, el YO abstracto - en palabras de J. Vicente (p. 201) «sujeto de la enunciación» - ordena en torno suyo todo el mensaje (esto determina el egocentrismo); pero, además, se produce una proyección del YO sujeto de la enunciación hacia el enunciado del que es responsable, lo que representa su componente subjetivo.

Así pues, el TÚ impersonal (o por extensión la segunda persona impersonal) se sitúa como fenómeno condicionado por la relación entre la deíxis personal y el enunciado. EI YO, como responsable del enunciado (entendido como «locutor perteneciente al mundo»), determina una relación de subjetividad que va del Enunciador al Enunciado y que suele incluir (gramaticalmente) la modalidad objetiva, la modalidad subjetiva y cualquier marca del enunciador presente en el enunciado; tal relación de subjetividad se manifiesta a través de la selección léxica. Precisamente por ello las expresiones deícticas en su actualización pueden responder más a una interpretación subjetiva que deíctica-egocéntrica, es decir, YO-TÚ no siempre denotan a los interlocutores ${ }^{17}$.

1 En el caso de las formas pronominales (Tú y otras formas del paradigma de segunda persona) la autora registra una frecuencia del $26^{\prime} 22 \%$ (referencia generalizadora), y en el caso de Ios mmorfemas verbales de segunda persona del singular, la proporción de usos con referencia generalizadora alcanza un $66^{\prime} 11 \%$, frente a un $333^{\prime} 88 \%$ con referencia al oyente-interlocutor (vid. págs. $175-176$ y pág. 176, nota 2 , en el estudio de Enríquez).

17 Hay que referirse en este punto necesariamente a J. Lyons (1980:581) para quien la deixis de persona «introduce una subjetividad inerradicable de la estructura semántica de las lenguas naturales», lo que implica que no siempre YO equivale al que está hablando, ni TÚ a aquel a quien alguien se dirige. 
El hablante desarrolla, en consecuencia, diferentes estrategias hacia el oyente con el fin de hacer más efectiva la información transmitida. Siempre que el oyente interpreta correctamente el contenido del enunciado la comunicación resultará exitosa.

En el terreno de la deíxis personal H. Haverkate (1984) sitúa tres clases de estrategias:

- estándar: p. e, cuando los pronombres personales gramaticalizan un tipo de relación social (USTED), o el empleo de un nombre común o propio como referencia de la $1^{\text {a }}$ persona (como presidente reclamo tu dimisión, como amigo, me resisto a admitirla);

- focalizadoras: dan preeminencia al papel del YO: se trata de usos como el pleonasmo mediante pronombres, nombres propios, nombres comunes, todos con el fin de realzar la egocentricidad del YO.

No sólo hay que aludir a este tipo de fenómenos focalizadores, puesto que para el español coloquial la nómina de usos es enorme; a tal efecto hay que reseñar las llamadas «expresiones autorreafirmativas», mencionadas por A. $\mathrm{M}^{\mathrm{a}}$ Vigara Tauste (1980:47), definidas como fórmulas de relleno que buscan la autorreafirmación del hablante, es decir, la necesidad de imponer la propia subjetividad del emisor: te lo digo yo, digo yo, cómo te lo diría yo...); un grupo especial dentro de estas estructuras son las denominadas atribuciones al interlocutor (interrogación retórica o apéndices justificativos como ¿sabes?, ¿entiendes?, ¿ves?...), algunas expresiones que indican mandato como imperativos intelectuales (calcule usted, mire usted...), o las expresiones autorreafirmativas encubiertas (el sujeto se escuda en un sujeto colectivo con pretensiones de objetividad (esa tierra, por lo que cuentan, debe de ser un sitio agradable)...

- desfocalizadoras: minimizan el papel del hablante; se trata de procedimientos como:

a) la impersonalización;

b) la supresión de la identidad del agente;

c) el empleo de la $1^{\circ}$ persona del plural inclusivo (plural de modestia en que el oyente comparte el punto de vista del hablante, o el hablante implica solidariamente al oyente);

d) el uso de referencias inclusivas que enmarcan al hablante, al oyente y a un $\mathrm{n}^{\text {o }}$ ilimitado de personas;

e) el recurso a expresiones de $2^{\circ}$ persona del singular mediante las cuales el hablante se distancia del enunciado...

Todos ellos constituyen fenómenos de subjetividad, pues a pesar de la presencia física del locutor (YO), la gramaticalización de ésta se realiza mediante la indeterminación del sujeto hablante o su ocultamiento dentro de otras categorías gramaticales. 
En definitiva, como ha observado recientemente A. Briz (1994), nos hallamos ante un caso de atenuación pragmática del YO, en concreto ante un caso de atenuación por impersonalización del YO, de modo que

«...el YO, con una intención persuasiva, presenta de forma confusa la referencia deíctico-personal a la hora de adjudicar a alguien lo que se va a decir: no soy yo, sino nosotros; somos todos y ninguno; es cualquiera; eres tú también... Todos ellos, sin embargo, se personalizan en el YO, latente».

En esencia, este tipo de fenómenos ya aparecía reseñado en W. Beinhauer (1985) en el marco de la CORTESÍA, o actitud del diálogo por la cual el YO ejerce su consideración hacia el hablante renunciando a su propio predominio.

En síntesis, hemos podido comprobar a través de diversos ejemplos y comentarios teóricos que, efectivamente, el empleo de TÚ impersonal es un fenómeno frecuente en el español que se habla actualmente. La escasa atención de las gramáticas al uso del español, salvo contadas excepciones, sólo puede obedecer a una causa: a su fundamentación escrita. Sin embargo, una gramática del español actual no puede obviar un uso tan extendido como éste (como tampoco otros) y algunas aportaciones teóricas (Enríquez, Vicente Mateu, E. Lorenzo (1989), M. Seco (1989)...) son suficientemente sólidas respecto a la cuestión como para otorgarle carta de naturaleza. La investigación sobre este tipo de problemas relacionados con la deíxis personal, deberá constituir un paso más en la elaboración de una futura "gramática" del español actual, capaz de superar algunos de los descuidos, imprecisiones o arcaísmos en que incurre a veces la normativa tradicional.

\section{Bibliografía}

ALBA DE DIEGO, V. y SÁNCHEZ LOBATO, J. (1980); «Tratamiento y juventud en la lengua hablada. Aspectos sociolingüísticos.» $B R A E X L$.

ÁLVAREZ MARTÍNEZ, Má ÁNGELES (1989): El pronombre I: Personales, Artículo, Demostrativos y Posesivos. Madrid. Arco-Libros.

BEINHAUER, W. (1964): El español coloquial. Madrid. Gredos. $3^{\text {a }}$ Ed. primera reimpresión, 1985.

BOURQUIN, G. (1965): «Niveaux, aspects et registres de langage» Linguistics $X I I I$.

BRIZ GÓMEZ, A. (1995): «La atenuación de la conversación coloquial. Una categoría pragmática», en Actas del I Simposio sobre el español coloquial. Aspectos del discurso oral. Almería. Universidad, Servicio de Publicaciones. 
BUTT, J. y BENJAMIN, C. (1988): A New Reference Grammar of Modern Spanish. London. Baltimore. Melbourne. Auckland.

COSERIU, E. (1981): «Los conceptos de Dialecto, Nivel y Estilo de lengua y el sentido propio de la dialectología». LEA $I I I-I$.

COSTA, J. y REDONDO, A. (1965): Syntaxe de l'espagnol moderne. Sedes.

CRIADO DE VAL, M. (1980): Estructura general del coloquio. Madrid. SGEL.

DÍAZ, F. (1985): El habla coloquial en el teatro de Antonio Gala. Oviedo. Universidad.

ENRÍQUEZ, E. V. (1984): El pronombre personal sujeto en la lengua española hablada en Madrid. Madrid. CSIC.

GOROSCH, M. (1967): «Un sujeto indeterminado o general expresado por la segunda persona del singular: tú», en Actes du IV Congrès de Romanistes Scandinaves dediés à Holger Sten. Copenhague, Akademisk Forlag.

GRANDGENT, CH. (1928): Introducción al latín vulgar. Madrid.

GREGORY y CARROLL (1978): Lenguaje y situación. Variedades del lenguaje y sus contextos sociales. México. FCE.

HAVERKATE, H. (1984): Speech acts, speakers and hearers. Amsterdam. JBFC.

HERNÁNDEZ, CÉSAR (1980): «Comentario de un texto coloquial», Hispanic Journal. $I V-2$.

HERNANDO CUADRADO, L. A. (1988): El español coloquial en El Jarama. Madrid. Nova Scholar.

JESPERSEN, O. (1975): La filosofía de la gramática. Barcelona. Anagrama.

KANY, CH. E. (1969): Semántica hispanoamericana. Madrid. Gredos.

LASALETTA, M. C. (1974): Aportaciones al estudio del lenguaje coloquial galdosiano. Madrid. Insula.

LÁZARO CARRETER, F. (1974): Diccionario de términos filológicos. Madrid Gredos.

LOPE BLANCH, J. M. (1984): «Novedades sobre la segunda persona y la expresión impersonal», en Athlon. Satura Grammatica in honorem Francisci R. Adrados, I. Madrid. Gredos (pp. 279-286).

LORENZO, E. (1989): «Relación interpersonal y expresión impersonal», en Rodríguez, F. (ed): Comunicación y lenguaje juvenil. Madrid. Fundamentos.

LYONS, J. (1980): Semántica. Barcelona. Teide.

NARBONA JIMÉNEZ, A. (1986): «Problemas de sintaxis coloquial andaluza», en $R S E L, 16-2$.

RAUH, G. (1984): Aspekte der Deixis II: Deiktische Dimensionen und die Verwendung deiktischer. Ausdrücke. LAUT A. 123.

ROSENGREN, P. (1974): Presencia y ausencia de los pronombres personales sujetos en español moderno. Stockholm. Acta Universitatis Gothoburgensis. 
SANDRU, T. (1988): «Algunos aspectos del lenguaje coloquial en la novela Mesa, sobremesa de A. Zamora Vicente», en Homenaje a Zamora Vicente. Madrid. Castalia.

SARMIENTO, R. y SÁNCHEZ, A. (1989): Gramática básica del español. Norma y uso. Madrid. SGEL.

SECO, M. (1985): «La lengua coloquial: Entre visillos de C. Martín Gaite», en Comentario de textos I. Madrid. Castalia. $4^{a}$ edición.

SECO, M. (1989): Gramática esencial del español. Madrid. Espasa-Calpe.

SILVA-CORVALÁN, C. (1988): Sociolingüística: teoría y análisis. Madrid. Alhambra.

STAMM. J. R. (1967): «El empleo impersonal del TÚ», en Romance Notes, 9. (pp. 338-340).

STEEL, B. (1985): A textbook of Colloquial Spanish. Madrid. SGEL.

VÄÄNÄNEN, V. (1985): Introducción al latin vulgar. Madrid. Gredos. $2^{a}$ edición de la $3^{\text {a }}$ francesa.

VANDEN BULCKE, P. (1991): Teoria y práctica del verbo español. Lovaina. Acco-Leuven.

VICENTE MATEU, J.A. (1990): La deixis. Egocentrismo y subjetividad en el lenguaje. Tesis doctoral. Inédita. Universidad de Murcia.

VIGARA TAUSTE, A. Mª (1980): Aspectos del español hablado. Madrid. SGEL. 